\title{
FRAGMENTOS DE TEORIA DO ESTADO
}

Zulmar Fachin

SUMARIO: 1 O Estado; 1.1 Origem da palavra; 1.2 Conceito; 1.3 Elementos; 2. Teorias sobre a origem do Estado; 2.1 Icoria da origem familiar; 2.2 Teoria da origem patrimonial; 2.3 Teoria da forca; 3 Evolucăo historica; 3.1 Estado Antigo; 3.20 Estado Grego; 3.30 Estado Romano; 3.40 Estado Medeval; 3.50 Estado Modeno; 4 Conchusāo 5. Bibliografia.

SUMMARY: 1. The State; 1.1. Ongin of the word; 1.2 Concept; 1.3. Elements; 2 Teories of the States orgin; 2.1. Teory of the familar origin; 2.2. Tery of the patrimonid origin; 2.3. Power Teory; 3. Historical ewoltion; 3.1 . The Old State; 3.2. The Gueh State; 3.3 The Romat State; 3.4. The Medieval State; 3.5. The Modern State; 4. Conclusion; 5. Bibliography.

UBERSICHT: 1.Der Staat. 1.1. Herkunft des Wortes. 1.2. Begriff. 1.3. Elemente. 2. Theorien uber die Entstehung des Stautes. 2.1. Theorie der Entstehung aus der Familie. 2.2. Theorie der Entstehung aus der Vermogensherschaft. 2.3. Machtheorie. 3. Geschichtiche Entwicklung 3.1. Der älteste Stadt. 3.2. Der griechische Staat 3.3. Der römische Staat 3.4. Der mittelalterliche Staat 3.5. Der modeme Siaat 4. Schlussfolgcrung 5. Bibliographie.

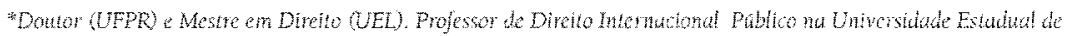

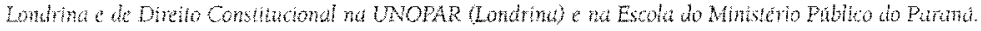


RESUMO: O presente trabalho tem por finalidade abordar aspectos relativos à teoria do Estado. E uma contribuição para conhecer a sociedade mais complexa jă idealizada pelo homem. Embora o século XXI tenha despertado sob o canto do neoliberalismo, o Estado continua a exercer profunda influência sobre as vidas das pessoas, intervindo a cada instante nas relaçóes publicas e privadas. Esta realidade complexa está a merecer detida reflexão dos estudiosos do Direito.

ABSTRACT: The present work has by purpose to approach aspects related to the theory of the State. It is a contribution to understand the most complex society already idealized by man. Although the 21 st century has wakened up under the song of the neoliberalism, the State continues to exerise deep influence on people's life, intervening all the time in public and private relationships. This complex reality deserves a detailed reflection from the Law specialists.

ZUSAMMENFASSUNG: Die vorliegende Arbeit beabsichtigt, Gesichtspunkte der Staatstheorie zu erörtern. Sie bildet einen Beitrag zur Kenntnis der komplexesten Gesellschaftsform, die der Mensch je idealisiert hat. Obwohl das 21. Jahrhundert unter dem Gesang des Liberalismus erwacht ist, ubt der Stata nach wie vor einen tiefen Einfluss auf das Leben der Menschen aus und greft in jedem Augenblick in die offendichen und privaten Beziehungen ein. Diese komplexe Wirklichkeit verdient eingehendes Nachdenken der Juristen.

PALAVRAS-CHAVE: Estado. Teoria. Elementos. Direito.

KEY-WORDS: State. Theory. Elements. Law.

SCHLUSSELWÖRTER: Staat. Theorie. Elemente. Recht. 


\section{O Estado}

Estado, realidade complexa, está presente na vida de cada um. Pode representar a salvaguarda dos valores mais caros da pessoa humana mas, ao reverso, pode se constituir tambem no "carrasco" que suprime ideais, sonhos e até mesmo a própria vida humana.

O Estado é onisciente, embora às vezes isto näo seja percebido. Conforme Georges Burdeau jamais alguém viu o Estado. Mas não se pode negar que é uma realidade. O lugar que ocupa em nossa vida cotidiana é de tal ordem que ele não poderia ser daí retirado sem que, ao mesmo tempo, ficassem comprometidas nossas possibilidades de viver. Ele comporta todas as paixões humanas: é generoso ou somitico, engenhoso ou estúpido, cruel ou complacente, discreto ou abusivo'.

Já se pode notar, então, que o Estado desempenha uma complexa gama de atividades. O homem nasce preso em seus laços e dele não tem o condão de emancipar-se, sem que, para isso, receba seu consentimento.

Perre Gaxotte, contemplando o Estado francês em página feliz resgatada por Darcy Azambuja tece o horizonte pelo qual, livre e soberbo, o Estado transita; a autoridade estatal aparece sob os traços de um funcionário, sentado detrás de uma secretaria e investido dos mais amplos direitos, inclusive o de nos transformar em soldado e de nos mandar receber pedradas em um motim de rua ou fragmentos de aço nos campos de batalha.

Afirma que o Estado ê um personagem eterno, imutável, idêntico a si mesmo de um extremo a outro do território. Na planicie ou na montanha, na tha de França ou na Lorena, ele aplica os mesmos regulamentos é cobra os mesmos impostos. É todo-poderoso porque sua espécie é numerosa, porque todos precisam dele, porque suas decisooses são apoiadas por uma policia ativa, uma dócil magistratura, numerosos regimentos. Conhece nossos rendimentos e faz o inventario de nossos bens; sabe se possuimos piano, automovel, cão ou bicideta. Educa nossos fithos e fixa o preco do pão; fabrica fosforos e vende fumo para o

${ }^{1}$ BURDEAU, Geoges, O Esculo, Trat. Gascais Fanco. S.l.: Europa-America, 1970, p. 14. 
nosso cigarro. É industrial, armador, comerciante e médico. Possui quadros, florestas, estradas de ferro, hospitais e o monopólio dos telefones. Se somos no sexo masculino, manda-nos comparecer diante dele e nos pesa, mede e examina o funcionamento dos nossos pulmöes, figado e coração. Não podemos dar um passo sem que ele seja avisado encontre pretexto para intervir. Um milhäo de franceses, pelo menos, estão a serviço dele, dois ou três mithoes são pensionados por elé, e outros aspiram ao mesmo ${ }^{2}$.

O Estado é essa realidade multifacetäria, que pode interferir, sob as mais variadas formas, na vida de cada pessoa. A liçăo do escritor francês levanos a refletir se ainda existe o Leviatã, referido por Thomas Hobbes, um dos teóricos do Absolutismo, que concebia o Estado como um Deus Mortal, acima do qual somente existia outro Deus: o Imortal.

Por constituir-se em uma realidade complexa, o Estado tem sido pouco estudado, e por isso mal compreendido. Estudá-lo e compreendè-lo, eis uma necessidade cada vez mais premente, que deve ser compartilhada.

Mas não basta estudá-lo. É preciso ter sensibilidade para captar esta obra que o sentir humano engendrou. Rousseau, ao tratar da morte do corpo político, afirmou lapidarmente: A constituição do homem é obra da natureza; a do Estado, obra de arte?.

\subsection{Origem da palavra}

Estado, do latim status, significa condição, posição, ordem. Neste sentido, falava-se em status romanus e status republicae.

O emprego da palavra Estado, como sinónimo de sociedade polftica, é recente. Data de 1513, e quem se encarregou de propagá-la foi Maquiavel, ao iniciar sua bela obra de Ciência Política: Todos os Estados, os dominios todos que já houve e que ainda há sobre os homens, foram, e são, republicas ou principados. Estava consagrada a expressão. A partir daí, passou-se a falar em État francês, State inglès, Stato italiano, Staat alemäo e Estado português.

\footnotetext{
2 AZAMBU]A, Darcy Teoria Geral do Estab. 35, ed. São Paulo: Globo, 1906, p. 146.

3 ROUSSEAU O Contuho Sotul. Trad. Antonio de Padua Denesi. Sao Pato Mantins Fontes, 1996, p. 107.

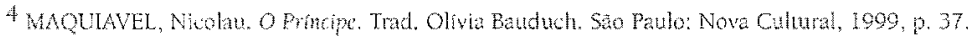


Mas a idéia de Estado como forma de organização política é mais antiga. Conforme anota Paulo Bonavides, a polis dos gregos e a civitas ou a república dos romanos traduziam a idéia de Estado. Durante o Império Romano, em sua fase de expansão, e mais tarde entre os germanos invasores, os vocábulos Imperium e Regnum também passaram a exprimir a idéia de Estado, nomeadamente como organização de domínio e poder 5 .

\subsection{Conceito}

Há uma enorme quantidade de autores que procuraram conceituar o Estado. Em razão disso e da complexidade do tema, a divergência é acentuada ${ }^{\circ}$. Após constatar a pluralidade de conceitos, Dalmo de Abreu Dallari observa duas orientaçōes fundamentais: uma baseada na noçāo de força, outra que toma por base a natureza jurídica do Estado.

No conceito de Estado ligado à força não está ausente a preocupação jurídica, mas o Estado é visto, antes de mais nada, como força que se põe a si próprio e que, por suas próprias virtudes, busca a disciplina jurídica. Nesta linha, o Estado pode ser conceituado como força material invisivel (León Duguit); unidade de dominação (Heller); institucionalização do poder (Burdeu); monopólio do poder (Gurvitch) e monopólio da força (Max Weber) ${ }^{7}$.

Outras teorias, porém, abordam o tema a partir da natureza jurídica do Estado. Por esta noção jurídica de Estado, não se ignora a força, mas dáse primazia ao elemento político: tenta-se mostrar que todos os demais fatores (elementos materiais) têm existência independente Cora do Estado e só se compreendem como componentes do Estado após sua integração de certa ordem jurídica. O Estado é tido como uma organização. E como

\footnotetext{
5 BONAVIDES, Paulo. Cienciu Poltica, 10. ed. São Paulo: Malheiros, 1999, p. 62.

6 ROMANO, Santi. Principios de Direito Constitucional Geral. Trad. Maria Helena Diniz. Sào Paulo: Revista dos Tribunais, 1977, p. 59 :

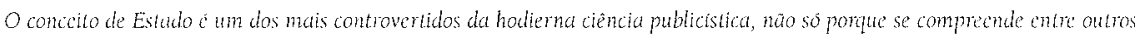
näo menos incerto, nas tamben, eprincipalmente, pela sta complexidade, o que dificulla o conhecinento de lodas as suas notas

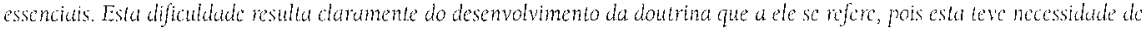

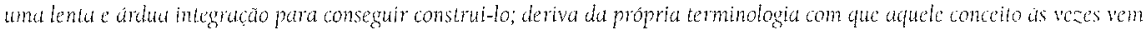
cxpresso, truduindo- the incomplete ou aproximadamente os varios aspectos.

7 DALLART, Dalmo de Abreu. Elcmentos de Teortas Geral do Estado, 21. ed. Sāo Paulo: Saraiva, 2000, p. II 16.
} 
organizacão precipuamente de pessoas o Estado passou a ser uma corporaça dotada de territónio

Apôs essas observaçōes, o autor conceitua o Estado como "ordem juridica soberana que tem por fim o bem comum de um povo situado em

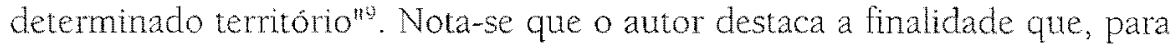
ele, constitui-se em elemento do Estado.

\subsection{Elementos}

A maioria dos autores afirma que os elementos constitutivos do Estado são três: território, povo e soberania. Têm sido acrescentados outros elementos, é neste sentido que variam as interpretaçoes. No âmbito deste estudo, aceitar-se-á a findlidade como um quarto elemento integrante do Estado.

O primeiro elemento constitutivo do Estado é o territorio. Trata-se do espaço físico sobre o qual o Estado se ergue: $e$ a area sobre a qual incide o poder estatal. A idéia de territónio é mais ampla do que parece num primeiro momento pois, além do teritorio propriamente dito, abrange também varias outras extensões, como embaixadas, mares, espaço aéreo e subsolo ${ }^{10}$.

O segundo elemento constitutivo do Estado é o povo. Sem este, o Estado năo existe, embola possa haver povo sem Estado como e o caso, por exemplo, dos palestinos, dos bascos, dos ianomâmis, dos curdos.

A Constituiça brasileira, em seu preambulo, fala em representantes do povo. $O$ art. $1^{\circ}$, parágralo único, afima que todo o poder emana do povo, que poderá exercê-lo por seus representantes ou diretamente, nos termos em que a própria Constituicão estabelecer.

\footnotetext{
8 tilom, 117

Glem, ibiden, p. Lls.

10 MUSEK, Carlos Robera, Curso de Direito Internacional Publico, 3. ed. 530 Panlo: LT, 2000, p. 40.

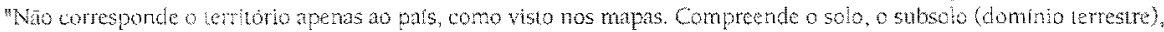

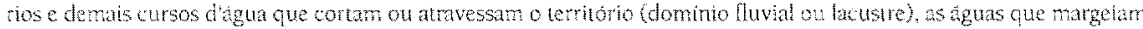

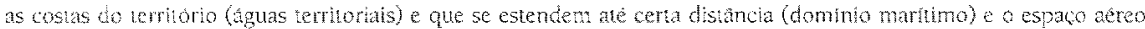

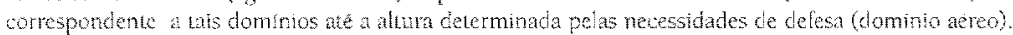


O conceito de povo tem suscitado confusoes. Não raro, confunde-se povo com nação ou com população. A idéia de povo é eminentemente juridica: é dada pelo Direito. O conceito de nação é dado pela Sociologia e envolve valores como cultura, usos, costumes, tradiçôes e ideais. Já a população é um conceito demográlico e estatístico.

Friedrich Müller, eminente professor alemāo, aborda a idéia de povo sob vários aspectos: como povo ativo, como instância global de atribuição de legitimidade, como ícone, como destinatário das pretensóes civilizatórias do Estado e como conceito de combate" .

O terceiro elemento integrante do Estado é a soberania. Poucos temas têm gerado tão profundas disputas entre os estudiosos quanto a idéra de soberania. Desde sua concepção até os dias atuais, os debates têm sido empolgantes. Duas idéas a caracterizam: a supremacia interna e a independencia externa.

Rousseau, a exemplo de Jean Bodin e Thomas Hobbes, foi teórico da soberania. Como se sabe, fez derivar da vontade geral a lei e o poder. Para ele, a soberania consiste no exercicio da vontade geral, que não pode ser transmitida. Daí por que afirmava ser a soberania inalienável e indivisível ${ }^{12}$.

Há, no entanto, autores que acrescentam outro elemento aos anteriormente analisados: a finalidade. Entre eles, encontram-se Alexandre Groppalli, Dalmo de Abreu Dallari e Manuel Garcia-Pelayo. O jurista italiano inseriu no próprio conceito de Estado a finalidade ao defini-lo como pessoa juridica soberana constituida de um povo organizado, sobre um territorio, sob o comando de um poder supremo, para fins de defesa, ordem, bem-estar e progresso social ${ }^{13}$.

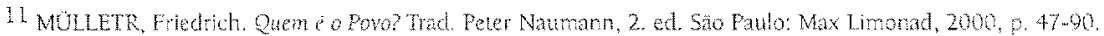

12 ROUSSEAL, op. cil. p. 33.

13 GRopPALl, Alexandre. Dotmo do Estado. Trad. Pauto Edmur de Souza Quelor, 2. ed. 5so Faulo: Saraiva, 1968, p. 265 .

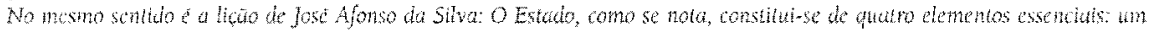

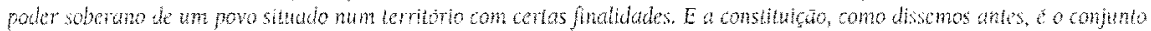

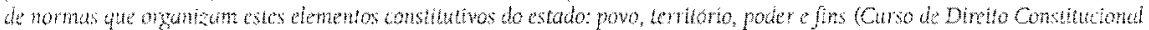
Positivo, 16. ce. So Puto: Maltetos, 1999. p. 102).
} 
Sustentando a mesma tese, Dalmo de Abreu Dallari entende que o Estado, como sociedade politica, tem um fim geral e constitui-se em meio para que os individuos e as demais sociedades possam atingir os respectivos fins particulares. O fim do Estado é a busca do bem comum de certo povo, que vive em determinado territôrio ${ }^{14}$.

Manuel García-Pelayo também identifica a finalidade como elemento constitutivo do Estado. Para ele, o Estado é uma organização que tem por objeto assegurar a convivência pacifica e a vida histórica de um grupo humanos.

\section{Teorias sobre a origem do Estado}

Muito já se escreveu acerca da origem do Estado. As teorias, cada qual a seu modo, procuram explicar como surgiu esse notável fenômeno da vida humana. As principais são a teoria da origem familiar (patriarcal e matriarcal), a teoria da origem patrimonial e a teoria da força.

\subsection{Teoria da origem familiar}

A familia é considerada a cellula-mater da sociedade. A partir dela, formaram-se pequenos agrupamentos sociais que, ampliados, foram se transformando nas grandes sociedades de hoje.

Aristóteles sustentou que o Estado surgira da ampliação da família. O Estado, forma mais elevada de comunidade, é composto de famílias. Quando várias familias se unem, constituem a primeira sociedade, que é a aldeia. Quando várias aldeias se unem numa única comunidade, grande o bastante para ser auto-

\footnotetext{
14 DALIART, OP, CHI, 2OOU, P. $19 \%$

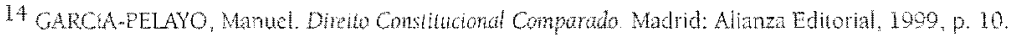

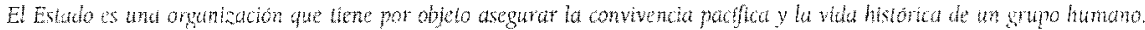

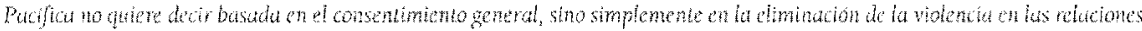

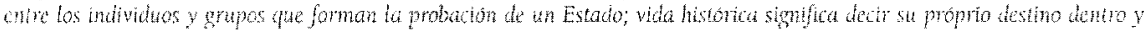
teghn las posibildades de andatation.
} 
suficiente, configura-se a cidade, ou Estado - que nasce para assegurar o vivere, depois de formado, é capaz de assegurar o viver bem. Portanto, a cidade-Estado é uma forma natural de associaçăo, assim como o eram as associaçoes primitivas das quais ela se originou ${ }^{i t}$. A familia, portanto, para o estagirita, e a fonte da qual se originou o Estado.

Afirma ainda o pensador grego que o Estado é uma criação da natureza e que o homem é, por natureza, um animal político. E aquele que por natureza e não por mero acidente, não tem cidade nem Estado, ou é muito mau ou muito bom, ou subumano ou super-humano. Aquele que for incapaz de viver em sociedade, ou que não tiver necessidade disso por ser auto-suliciente, será uma besta ou um deus, não uma parte do Estado. E, preocupado com a justiça, afirmava que o homem, quando perfeito, é o mehor dos animais; quando apartado da lei e da justiça, porém, é o pior de todos, pois a justiça é o vinculo dos homens no Estado ${ }^{17}$.

O homem, animal político, nasceu para viver em sociedade. E, de todas as formas de sociedade, a mais importante é o Estado, à qual todos se acham vinculados.

Observa Sahid Maluf que, em regra, o Estado se forma pela reunião de vârias familias. Os primitivos Estados gregos foram grupos de clas. Estes grupos formavam as gens; um grupo de gens formava a fratria; um grupo de fratrias formava a tribu, esta se constituia em Estado-cidade (polis). O Estado-cidade evolutu para Estado nacional ou plurinacionals.

Sustentam os adeptos desta teoria que o Estado é resultado da ampliação da sociedade familiar. Há, neste sentido, duas correntes doutrinárias: uma, chamada patriarcal, sustenta que o Estado nasceu do núcleo familiar, submetido à autoridade do pai; para a outra, chamada matriarcal, o Estado nasceu de um núcleo familiar, cuja autoridade era exercida pela mãe.

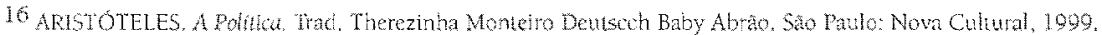
(Coleçäo Os Pensudiares, p. 1.45 1.46)

17 Item. . 148.147.

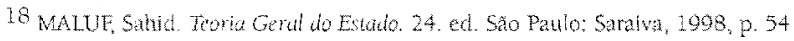


O pai, ao longo do tempo, foi considerado o chefe da sociedade conjugal. E, com a ampliação da família, sua autoridade passou a ser exercida sobre todo o agrupamento social. Remota no tempo, e hoje bastante criticada, a teoria da onigem patriarcal do Estado pode ser aceita não como critério absoluto, mas como regra.

A teoria da origem familiar do Estado tem, porém, outra concepcaão. Forte corrente doutrinária sustenta que a origem do Estado está na autoridade da mãe e não na do pai. Os delensores da teoria matriarcal, ou matriarcalistica, sustentam que o primeiro núcleo familiar foi dominado pela mãe, e isto por uma razão de natureza fisiológica: a maternidade, ao contrário da paternidade, é sempre centa (mater semper cerla).

Neste sentido, a lição de Sahid Malul: Assim, como era geralmente incerta a patemidade, teria sido a mãe a dirigente e autoridade suprema das primitivas familias, de maneira que o cla matronimico, sendo a mais antiga forma de organizaça familiar, seria ofundamento da sociedade civit".

Esta tese tambëm é contestada, pois, ainda que em tais casos a mãe tenha representado o centro da familia, não ha provas de que ela haja excrido um poder igual ao do pater-familias ${ }^{20}$. Não se nega a certeza da maternidade e que a mäe tenha representado o núcleo da unidade lamiliar. Todavia, apesar disso, a mãe não exerceu poder sobre a familia. Isto foi feito, certamente, pelo pai.

A crítica que sofre a teoria da origem familiar do Estado, tanto no seu desdobramento patriarcal quanto matriarcal, consiste em que se estaria confundindo origem do Estado com origem da sociedade. A familia seria uma unidade social; o Estado, uma unidade política.

Esta crítica é bem sintetizada por Darcy Azambuja: Que a sociedade em geral, ogenero humano, deriva necesariamente da familia, e fora de tola divida e por isso se diz com razäo que a familia é a celula da soctedade. Năo se pode, porém, aplicar o mesmo raciocinio ao Estado. Não é de todo improvável que en

19 klem, p. 55

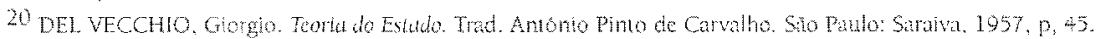


alguma regiăo da terra o desenvolvimento de uma familia tenha dado origem a um Estado determinado. Esse processo, no entanto, näo foi geral? ${ }^{2}$.

Neste sentido, embora em alguns casos pode-se falar que os Estados nasceram a partir da familia, é de se reconhecer que esta deu origem à sociedade. Foi a partir da sociedade familiar que nasceu a sociedade civil.

\subsection{Teoria da origem patrimonial}

Parece ter sido Platāo o primeiro a falar na origem economica do Estado. Sustentava esse pensador grego que os homens deveriam desenvolver atividades economicas distintas para facilitar a própria sobrevivência. Deste modo, ensinava, deveria haver teceläs, agricultores, pedreiros, sapateiros, ferreiros, carpinteiros, todos produzindo economicamente e de cujos benefícios a coletividade poderia usufruir para a própria subsistencia. Essas profissōes econômicas deveriam estar unidas e, desta uniäo, nasceu a cidade (Estado) ${ }^{22}$.

E o que se nota desta lição do eminente pensador: O que causa o nascimento a uma cidade, penso eu, ca impossibilidade que cada individuo tem de se bastar a si mesmo e a necessidade que sente de uma porçăo de coisas; ou julgas que existe outro motivo para o nascimento de uma cidade? Portanto, um homem une-se a outro homem para determinado emprego, outro ainda para outro emprego, $e$ as multiplas necessidades reunem na mesma residencia um grande numero de associados e auxiliares; a esta organização demos o nome de cidade, nào fot? $?^{23}$.

Tratando-se do surgimento do Estado sob uma óptica patrimonial, não se pode olvidar John Locke. O grande nome do liberalismo inglês deteve-se a analisar a vida do homem em estado de natureza e em estado de guerra. No estado de natureza qualquer um pode fazer valer a lei, executando-a a seu próprio modo. Isto gera um estado de guerra, em que o homem está em

21. AZAMBUHA, op , it., 98.

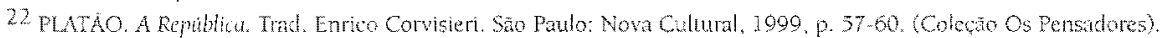
23 tum, p. 54 
conflito com seu semelhante. No estado de guerra o homem não consegue sobreviver.

O homem carece de algumas necessidades, como a de ter e conservar a sua propriedade, da qual deseja desfrutar em paz e em segurança. É para proteger este bem juridico fundamental que o homem necessitou do Estado: O fim maior e principal para os homens unirem-se em sociedades politicas e submeterem-se a um governo é, portanto, a conservação de sua propriedade ${ }^{24}$. Neste sentido, a propriedade motivou o surgimento do Estado.

Mais recentemente, Fridrich Engels sustentou a origem econômica do Estado. Para este autor, o Estado surgiu com o escopo de assegurar a propriedade particular e garantir a divisão entre duas classes: a dos que são e a dos que näo são proprietários. O Estado então teria sido instituído pelos proprietarios, e a razão de sua origem era apenas a de garantir-lhes a propriedade.

Neste sentido, Friedrich Engels, falando do surgimento do Estado Grego, observou que na Grécia Antiga a riqueza era valorizada e respeitada como bem supremo a propriedade permitia a dominação de uns sobre os outros. Para garanti-la, os dominadores precisavam de um instrumento que pudesse ser manuseado em seu beneficio.

Escreveu então o fiel amigo de Marx: Faltava apenas uma coisa: uma instituição que não só assegurasse as novas riquezas individuais contra as tradicōes comunistas da constituiçäo gentilica; que näo so consagrasse a propriedade privada, antes tão pouco estimada, e fizesse dessa consagração santificadora o objetivo mais elevado da comunidade humana, mas também imprimisse o selo geral do reconhecimento da sociedade às novas formas de aquisição da propriedade, que se desenvolviam umas sobre as outras - a acumulação, portanto, cada vez mais acelerada das riquezas: uma instituça que, em uma palavra, näo só perpetuasse a nascente divisão da sociedade em classes, mas também o direito de a classe possuidora explorar a näo-possuidora e o dominio da primeira sobre a segunda. E essa instituição nasceu. Inventou-se o Estado ${ }^{25}$.

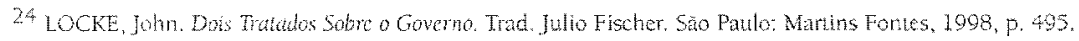

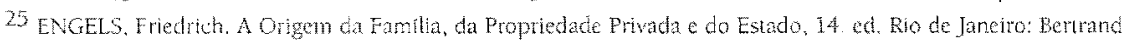
Eatail, 1997, p. 19-120.
} 
Sob essa optica, o Estado nasceu com escopo definido: reconhecer, legitimamente, as riquezas individuais e a propriedade privada, assegurando o poder dos proprietários sobre os não proprietários. Nesse sentido, com a desejada extinçăo das classes sociais, o Estado desapareceria, pois na razão de seu surgimento - assegurar o domínio de uma classe sobre outra - já não existiria.

\subsection{Teoria da força}

A teoria da força, ou da origem violenta do Estado, tem em suas fileiras grandes defensores, a maioria deles sociologos que fizeram época. Pontilicam Thomas Hobbes, Franz Oppenheimer, Glumpowicz, Trotsky, Max Weber e ourros.

Para Thomas Hobbes, o homem no início vivia em estado de natureza. Nesse estado, inexistindo qualquer convenção para regrar condutas, o homem tinha o direito sobre todas as coisas e nada the impunha o dever de respeito a seu semelhante. A natureza deu a cada um direito a tudo; isso quer dizer que, num estado puramente natural, ou seja, antes que os homens se comprometessem por meio de convençóes ou obrigaços, era licito fazer o que cada um quisesse, e contra quem jughasse cabivel, e portanto possuir, usar e desfrutar tudo o que quisesse ou pudesse obter ${ }^{26}$.

Havia entre os homens igualdade natural. Todos podiam fazer o que quisessem. Isto fez o mais forte estabelecer dominio sobre o mais fraco. Tal situação provocava insegurança e medo. E foi o medo que levou os homens a celebrar um pacto entre si, fazendo-os se sentir mais seguros.

O pacto social, portanto, não teria surgido em decorrëncia da vontade (como em Rousseau), mas do medo que envolvia os homens. A origem de todas as grandes e duradouras sociedades não provem da boa vontade reciproca que os homens livessem uns para com outros, mas do medo recíproco que uns timham dos outros ${ }^{27}$.

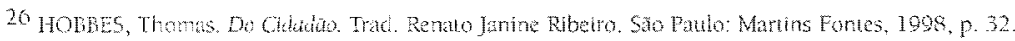

27 MORnEs, op. at, 1998, p. 28. 
No estado de natureza, os homens estão $\mathrm{em}$ permanente estado de guerra entre si. Guerra de todos contra todos: o homem é lobo do homem. Nâo havera como negar que o estado natural dos homens, antes de ingressarem na vida social, näo passava de guerra, e esta näo ser uma guerra qualquer, mas uma guerra de todos contra todo ${ }^{28}$. E, mesmo após as disputas, era necessário garantir o domínio do mais forte, vencedor, sobre o mais fraco, vencido.

É lugar-comum na doutrina a afirmativa lapidar de Trotsky: todo Estado se funda na força. Os seguidores do pensador russo sustentam que na origem do Estado está a violência dos mais fortes. No estágio primitivo, os agrupamentos de pessoas viviam em permanente estado de guerra. O grupo vencedor precisava de un instrumento que lhe permitisse manter o domínio sobre o grupo vencido. Com tal finalidade, idealizou-se o Estado, por meio do qual o uso da força passou a ser legítimo.

Esta idéia foi magistralmente sintetizada por Max Weber, ao lecionar que o Estado reivindica para si o monopólio do uso da força: Em nossos dias, a relação entre o Estado e a violencia é particularmente intima. Em todos os tempos, os agrupamentos politicos mais diversos - a começar pela familia recorreram à violencia fisica, tendo-a como instrumento do poder. Em nossa época, entretanto, devemos conceber o Estado contemporaneo como uma comunidade humana que, dentro dos limites de determinado território - a noção de território corresponde a um dos elementos essenciais do Estado - reivindica o monopólio do uso legitimo da violencia fisica. E, com efeito, próprio de nossa época o nāo reconhecer, em relação a qualquer outro grupo ou aos individuos, o direito de fazer uso da violéncia, a não ser nos casos em que o Estado o tolere; o Estado se transforma, portanto, na unica fonte do direito à violencia ${ }^{29}$.

Nota-se da lição do sociólogo alemão que o Estado surgiu para ser utilizado como instrumento de dominação do vencedor sobre o vencido. Aquele, para assegurar seu domínio sobre este, instituiu o Estado, que passou a deter o monopólio do uso legítimo da força física. Por meio do Estado, o mais forte (vencedor) passou a dominar legitimamente o mais fraco (vencido).

\footnotetext{
28 Hem, p. 33

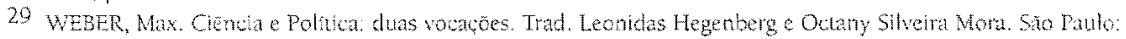
Culturex, 1986, p. 56
} 


\section{Evolução histórica}

A realidade estatal é dinâmica. Evolui com o tempo. Assim, constatar a evolução histórica do Estado é imprescindivel para compreendè-lo. Sob uma perspectiva cronológica, pode-se falar que o Estado viveu as seguintes lases: Estado Antigo, Estado Grego, Estado Romano, Estado Medieval e Estado Moderno.

\subsection{O Estado Antigo}

O Estado Antigo é também chamado Estado Oriental ou Estado Teocrático. Tinha cunho eminentemente religioso, mistico. Remonta a cerca de 3000 anos antes da Era Cristã e se formou na região da Baixa Mesopotâmia, às margens dos rios Tigre e Eufrates.

Em rigor, existiram mesmo vários Estados na Antiguidade. Todos com caracteristicas semelhantes.

Podem ser colhidas na doutrina as principais carateristicas que marcaram o Estado Antigo: a) religiosidade: o governante exercia o poder em nome da vontade de uma divindade; b) concentração de poderes: um mesmo governante acumulava as funções militar, judicial, sacerdotal e de coleta de impostos, denotando assim a natureza unitária do poder; c) heterogeneidade: era formado e mantido pela lorça das armas; d) instabilidade terntorial: a base territorial do Estado não era definida aumentava ou diminuía conforme as conquistas ou as derrotas do imperador; e) năo eram Estados nacionais, mas agrupamentos de pessoas que reuniam dilerentes raças conquistadas e escravizadas; D diferenças de classe: os nobres, os chefes militares e os sacerdotes de culto nacional gozavam de regalias, enquanto os párias e os escravos viviam à margem da lei; g) confusão entre as idéias de família, Estado, religião e organização industrial ${ }^{30}$.

30 MALUE, op cit, p. 39-40, DALLARI, op cit. p. 62-63: MENEZES, Aderson. Teoria Gerdi do Estade, 8. ed. Rio de Janeino: Forense, 1999, p. 106-109. 
Dessas características, duas são destacadas por Dalmo de Abreu Dallari: a natureza unitária e a religiosidade. De um lado, o Estado Antigo sempre aparece como uma unidade geral e näo admite qualquer divisão interior; nem territorial nem de funçôs. A idéia da natureza unitária é permanente $e$ persiste durante toda a evoluçao politica da Antiguidade ${ }^{3 ?}$.

De outro lado, o autor constata a marcante influência religiosa, já que a autoridade dos governantes $e$ as normas de comportamento individual e coletivo eram tidas como expressão da vontade de um poder divino. Esse cunho teocrático significa estreita relação entre o Estado e a divindade. Isto pode ocorrer de duas formas diferentes: a) o governo é unipessoal, e o governante é considerado um representante do poder divino, já que se confundia, as vezes, com a própria divindade; b) o poder do governante é limitado pela vontade da divindade cujo veículo é um órgão especial: a classe sacerdota ${ }^{32}$.

\subsection{Estado Grego}

A Grécia foi o berço da Filosofia em que pontificaram Platão e Aristóteles. Ali, as classes mais privilegiadas puderam viver a Democracia. Em Atenas, por exemplo, as pessoas reuniam-se em praça pública para discutir e decidir sobre os problemas da coletividade. Embora se saiba que apenas uma parcela dos atenienses tivesse direito à voz, o debate existia $e$ aquele tempo tem servido de inspiração para muitos estudiosos.

O Estado Grego era uma monarquia patriarcal baseada na aristocracia. Cada cidade tinha um Rei, um Conselho de Anciàos - orgäo principal do Estado - e uma Assembléia Geral dos Cidadãos, encarregada de resolver os casos de maior importancia. Com o tempo, passou a ser uma república democrática direta, mas ainda apoiada na aristocracia.

As idéias políticas fervilhavam. A Constituição de Atenas foi a materialização da democracia grega. Relata Sahid Maluf que o Conselho dos

\footnotetext{
31 DALLARI, op cil., p, $62-63$

32 un .63 .
} 
Anciãos, deixando de ser órgão principal do Estado, passou a ser eletivo e subordinado à Assembléia dos Cidadãos. As magistraturas tornaram-se temporárias; os governantes eram escolhidos e nomeados pela Assembléia Geral, para mandato de um ano. Os cidadãos investidos em funçōes públicas eram obrigados a prestar contas periódicas, e, quando assim não procedessem, eram citados diante da Assembléia popular ${ }^{33}$.

O Estado Grego era o Estado-cidade, a Polis, onde não se confundiam a Religião e o Estado. Ao contrário do que ocorria no Estado Antigo, Estado e Religião estavam separados. Os poderes temporal e divino não se misturavam.

\subsection{Estado Romano}

Se a Grécia loi o berço da Filosofia, Roma foi o esplendor do Direito. As instituiçóes juridicas nasceram à beira do Tibre e, petrificadas pelo Tempo, permanecem até hoje como rochedo a sustentar o ordenamento jurídico de significativo número de países. Enumerar aqui os institutos juridicos que herdamos do Direito Romano seria temerário, dada à sua vasta quantidade.

Pode-se, porem, afirmar que o Estado Romano erguel-se sobre os alicerces da família. Esta dividia-se em familia propriamente dita e gens (gentes). A gens teria sido o núcleo a partir do qual nasceu o Estado (Civitas). O primitivo Estado-Cidade dos romanos, portanto, era uma reunião de gens. As gentes reunidas formavam a Curia; várias Curias formavam a Tribu; e diversas Tribus constituiam a Civitas. Esta possuia um Senado cujos membros eram os pater-familias. Por isso mesmo, ainda no decorrer do Império, os senadores conservavam o titulo tradicional de pater ${ }^{34}$.

Os romanos eram marcados pelo desejo de expansão. À medida que consolidavam a conquista de novos espaços territoriais, materializavam a integração juridica dos povos dominados, ampliando ilimitadamente a area

33 MALUF, on all. 98

34 Lden, P. 102. 
de abrangencia de seu Estado. Depois, os romanos passaram a utilizar do Direito como instrumento para tornar definitivas as vitórias dos seus exércitos.

$O$ Direito protegia o cidadâ romano, de tal modo que as pessoas que pertenciam ao território conquistado por Roma se sentiam seguras não apenas porque vislumbravam a possibilidade de ser cidadãs romanas, mas também porque passavam a ter a proteção de seu Direito. Os romanos foram os primeiros a perceber a importăncia do Direito para a convivência social. Quando instrumentalizou o Direito, Roma estabeleceu o domínio sobre o mundo.

Em pelo menos dois pontos o Estado Romano lembrava o Estado Grego: a participação de parte significativa do povo nas decisoes de governo e a separaçăo entre Estado e Religiäo.

povo participava diretamente do governo. Nos comicios, os cidadãos decidiam sobre questões de importância para a coletividade. No entanto, como se sabe, poucos eram os que tinham direto de participar e decidir: somente os cidadãos romanos.

Estado e a Religiäo passaram a ser duas ordens distintas e o poder divino deixou de ser invocado como fundamento do poder terreno.

\subsection{Estado Medieval}

Com a derrocada do Império Romano, nasceu o Estado Medieval, Trata-se de um dos periodos mais difceis, tremendamente instavel e heterogenen, não sendo tarefa das mais simples a busca das caracteristicas de um Estado Medieval ${ }^{5}$.

Mesmo em face da dificuldade apontada pelo eminente Professor, pode-se dizer que as principais características do Estado Medieval foram: a) a forma monárquica de governo; b) a supremacia do direito natural; c) a

35 DALLART, op, at. p. 66. 
confusão entre direito público e direito privado; d) a descentralização feudal; e) a submissão do poder temporal ao poder espiritual.

Os elementos mais importantes que marcaram o Estado Medieval foram o cristianismo, as invasões bárbaras e o feudalismo.

o cristianismo buscava assegurar a igualdade entre os homens, de modo que estes não podiam ser tratados como se uns valessem mais do que outros. Feitos à imagem e semelhança de Deus, todos têm o mesmo valor. Entre estes, não pode haver distinção.

Mas na vigência do cristianismo passou-se a fazer outra espécie de distinção: a dos homens tementes e nãotementes a Deus. O cristianismo substituiu a distinça entre nacionais e bâbaros, livres e escravos, pela distinçăo entre crentes e incréus, a unica que conta, definitivamente, para a justiça divina ${ }^{35}$.

Os bárbaros haviam invadido o Império Romano. A desordem era visivel, pois não havia unidade de comando. Os limites lerritoriais eram incertos $e$ as guerras, constantes. Deste modo se percebe que, no Estado Medieval, a ordem era sempre bastante precaria, pela improvisaça das chefias, pelo abandono ou pela transfomacão de padröes tradicionais, pela presença de uma burocracia voraz e quase sempre todo-poderosa, pela constante situaça de glerra, $c$, incyitavelmente, pela propria indefinica a das fronteiras politicas ${ }^{37}$.

O feudalismo era alicerçado na propriedade da terra. Os senhores feudais detinham a posse de muitas extensöes de terras e cediam-nas para que outras pessoas as explorassem e, como pagamento, lhes dessem uma parte da produção. Caracterizou-se esse sistema pela exploração do trabalho humano.

\subsection{O Estado Moderno}

Tem sido aceito pela doutrina que o Estado Moderno nasceu a partir dos tratados da paz de Vestfátia ${ }^{38}$. Passou-se, então, das monarquias

\footnotetext{
36 PERELMAN, Chatn. Etha Dirito. Trad. Mata Emmana Galva G. Pereira. Sto Patlo: Martins Fontes, 1996, p 31.

37 DALLART, Op, CI. p. 6869.

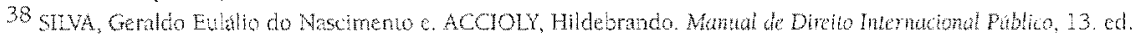
Sico Paula: Saraiva, 1998 , p. 9.
} 
medievais às monarquias absolutistas, cuja existência consiste na transição para os tempos modernos.

A fonte do poder do monarca era considerada divina, pois que ele o recebia diretamente de Deus. Deste modo, o monarca portava-se como proprietário de seu reino: Assim como a propriedade é direito exclusivo do dono sobre a coisa, o poder de imperium é direito absoluto do Rei sobre o Estado ${ }^{30}$.

Este absolutismo, que unificava o poder nas Monarquias, teve grandes vultos do pensamento da Humanidade a inspirá-lo. Pontificaram Nicolau Maquiavel e Thomas Hobbes. Foi neste contexto que Luiz XIV afirmou: LEtat c'est moi.

Mas tal regime, contrário à natureza humana, haveria de encontrar objeçóes. E elas vieram de modo contundente na força intelectual de John Locke. Este pensador ingles foi quem mais soube esboçar a reaçăo antiabsolutista.

Opondo-se ao poder absoluto que advinha da concentração de poderes, Locke previu que o poder estatal deveria ser distribuido entre vários órgãos, cada qual encarregado de uma tarefa especifica. Um orgäo deveria legislar, outro executar as leis e outro solucionar os litígios. Com isso, o monarca deixara de enfeixar em suas mãos todo o poder estatal, e Locke constituiu-se um dos notáveis ideólogos da doutrina da separação de poderes $^{40}$.

Por fim, após o pensamento liberal de Locke, surgiram outros pensadores como Rousseau e Montesquieu e, mais tarde, as revoluções Americana e Francesa que, juntando-se à Revoluçăo Inglesa, trouxeram a marca do Estado Liberal. A partir daí, passou-se a estabelecer proteção juridica aos direitos mais importantes da pessoa humana.

\footnotetext{
39 MALUE, on, tit. p. 120.

40 LOCKE, op dt, $502-528$
} 


\section{Conclusão}

- O Estado é uma realidade complexa, presente na vida de cada pessoa. Embora possa ser localizada em tempos remotos, a palavia Estado foi empregada pela primeira vez por Maquiavel, em 1513.

- Os elementos do Estado são o povo, o territorio e a soberania, mas alguns autores falam também em finalidade.

- Há inumeras teorias que procuram justificar o surgimento do Estado. As principais são teoria da origem lamiliar (patriarcal e matriarcal), teoria da origem patrimonial e teoria da força.

- A teoria da origem familiar, que teve em Aristóteles seu principal defensor, sustenta que a tamilia é o núcleo com base no qual surgin - Estado. Há, neste sentido, duas correntes doutrinárias: uma, a patriarcal, sustenta que o Estado nasceu do nucleo familiar cuja autoridade era exercida pelo pai; para outra, a chamada matriarcal, - Estado nasceu do núcleo familiar cuja autoridade era exercida pela mãe.

- Para alguns autores, como Platão e Friedrich Engels, a origem do Estado está na propriedade. O Estado nasceu para servir de instrumento garantidor da propriedade, legitiminado-a e protegendo-a.

- A teoria da força, apoiada nas lições de Thomas Hobbes e Max Weber, sustenta que o Estado é fruto da supremacia dos vencedores sobre os vencidos. Ao término dos conflitos nos quais os homens sempre estiveram envolvidos, o vencedor necessitava de um instrumento capaz de legitimar a força com a qual dominava o vencido. Nasceu o Estado.

- O Estado é uma realidade complexa e dinâmica, que evoluí ao longo do tempo. Sob uma perspectiva histórica, o Estado viveu as seguintes lases: Estado Antigo, Estado Grego, Estado Romano, Estado Medieval e Estado Moderno. 


\section{BIBLIOGRAFIA}

ARiSTOTELES A Política. Coleço os Pensadores. Traducto de Therezinha Monteiro Deutsch Baby Abrão. Săo Paulo: Nova Cultural, 1999

AZAMBUJA, Darcy. Teoria Geral do Estado, 35. ed 5ä paulo: Globo, 1996.

BONAYIDES, Patlo. Ciência politica, 10. ed. Sắ Patlo: Malheiros, 1999.

BURBEAU, Georges. O Estado. Traduça de Cascais Franco. S.1. Europa-America, 1970.

DALlari, Dalmo de Abreu. Elementos de Teoria Geral do Estado, 21. ed. Sâo Faulo: Sarava, 2000

DEL VECCHIO, Giorgio. Tcona do Estado. Thaduçao de António Pinto de Caravalho. São Paulo: Saraiva, 1957

ENGELS. Eriedrich. A Origem da Familia, da Propriedade Privada e do Estacio, 14. ed. Rio de Janeiro: Berrand Brasil, 1977.

GARCIA-PELAYO, Manuel. Direito Constitucional Comparado. Madrid: Alanza Editoriai, 1999

Groppalu, Alexandre. Doutrina do Estado. Traducăo de Paulo Edmur de Souza Queiroz, 2. ed. São Paulo: Saraiva, 1968

HUSEK, Calos Roberto. Curso de Direito Internacional Publico, 3. ed. Săo Paulo: LTr, 2000.

HOBBES, Thomas. Do Cidadão. Traduça de Renato Janine Ribeiro. São Paulo: Martins Fontes, 1998

LOCKF, Fohn. Dois Tratados Sobre o Governo. Traduca de Juho Fischer, Săo Paulo

MAQUIAVE, Nicolau. O Principe. Traduça de Olrvia Bauduch. Sño Paulo: Nova Cultural, 299

MALUF, Sahid. Teoria Geral do Estado, 24. ed. Säo Paulo: Samiva, 1998.

MANEZES, Aderson. Teoria Geral do Estado, 8. ed. Rio de Janeiro: Forense, 1999

MULLER, Friednch Quem e o Povo? Traduço de Naumann, 2. ed. Săo Patlo: Max Limonad, 2000.

PLATÃO A República de Platăo. Coleçâo os pensadores. Traduçăo de Enrico Covisien Săo Paulo Nova Cultural, 1999.

PERELMAN, Chain, Etica e Direito. Traduça de Matia Emantina G. Pereira. Säo Paulo: Martins Fontes, 2996

ROMANO, Santi Principios de Direito Constitucional Geral. Taduçăo de Maria Helena Diniz, Så Paulo: Revista dos Tribunais, 1977.

ROUSSEAU. O Contrato Social. Traduça de Antonio Padua Danesi. Săo Paulo: Matins Fontes, 1996 SIVY, Gerado Eulálio do Nascimento e. ACCIOLY, Hildebrando, Manual de Direito Internacional Público, 13 ed. Să Paulo: Saraiva, 1998.

WEBER, Max. Cîncia e Politica: duas vocaçôes. Tradução de Leonidas Hegenberg e Octany Silvetra Mota. Sao Paulo: Cultrix, 1968. 